(C) 2021, The Authors. Published by Elsevier Inc. and Fass Inc. on behalf of the American Dairy Science Association ${ }^{\circledR}$. This is an open access article under the CC BY-NC-ND license (http://creativecommons.org/licenses/by-nc-nd/4.0/).

\title{
Genetic analysis of resilience indicators based on milk yield records in different lactations and at different lactation stages
}

\author{
M. Poppe, ${ }^{1 *} \oplus$ G. Bonekamp, ${ }^{1} \oplus$ M. L. van Pelt, ${ }^{2} \odot$ and H. A. Mulder ${ }^{1} \oplus$ \\ ${ }^{1}$ Wageningen University \& Research, Animal Breeding and Genomics, PO Box 338, $6700 \mathrm{AH}$ Wageningen, the Netherlands \\ ${ }^{2}$ Cooperation CRV, Animal Evaluation Unit, PO Box 454, 6800 AL Arnhem, the Netherlands
}

\begin{abstract}
Resilience is the ability of cows to cope with disturbances, such as pathogens or heat waves. To breed for improved resilience, it is important to know whether resilience genetically changes throughout life. Therefore, the aim was to perform a genetic analysis on 2 resilience indicators based on data from 3 periods of the first lactation (d 11-110, 111-210, and 211-340) and the first 3 full lactations, and to estimate genetic correlations with health traits. The resilience indicators were the natural log-transformed variance (LnVar) and lag-1 autocorrelation $\left(\mathrm{r}_{\text {auto }}\right)$ of daily deviations in milk yield from an expected lactation curve. Low LnVar and $r_{\text {auto }}$ indicate low variability in daily milk yield and quick recovery, and were expected to indicate good resilience. Data of 200,084 first, 155,784 second, and 89,990 third lactations were used. Heritabilities were similar based on different lactation periods $(0.12-0.15$ for LnVar, 0.05-0.06 for $\mathrm{r}_{\text {auto }}$ ). However, the heritabilities of the resilience indicators based on full first lactation were higher than those based on lactation periods ( 0.20 for LnVar, 0.08 for $r_{\text {auto }}$ ), due to lower residual variances. Heritabilities decreased from 0.20 in full lactation 1 to 0.19 in full lactation 3 for LnVar and from 0.08 to 0.06 for $r_{\text {auto }}$. For LnVar, as well as for $r_{\text {auto }}$, the strongest genetic correlation between lactation periods was between period 2 and 3 (0.97 for LnVar, 0.96 for $\mathrm{r}_{\text {auto }}$ ) and the weakest between period 1 and 3 (0.81 for LnVar, 0.65 for $\mathrm{r}_{\text {auto }}$ ). Similarly, for both traits the genetic correlation between full lactations was strongest between lactations 2 and 3 (0.99 for LnVar, 0.95 for $\mathrm{r}_{\text {auto }}$ ) and weakest between lactations 1 and 3 (0.91 for LnVar, 0.71 for $\mathrm{r}_{\text {auto }}$ ). For LnVar, genetic correlations with resilience-related traits, such as udder health, ketosis, and longevity, adjusted for correlations with milk yield, were almost always favorable $(-0.59$ to 0.02$)$. In most cases these genetic correlations were stronger based
\end{abstract}

Received July 8, 2020.

Accepted September 18, 2020.

*Corresponding author: marieke.poppe@wur.nl on full lactations than on lactation periods. Genetic correlations were similar across full lactations, but the correlation with udder health increased substantially from -0.31 in lactation 1 to -0.51 in lactation 3 . For $\mathrm{r}_{\text {auto }}$, genetic correlations with resilience-related traits were always favorable in lactation period 1 and in most full lactations, but not in the other lactation periods. However, correlations were weak $(-0.27$ to 0.15$)$. Therefore, as a resilience indicator for breeding, LnVar is preferred over $r_{\text {auto }}$. A multitrait index based on estimated breeding values for LnVar in lactations 1, 2, and 3 is recommended to improve resilience throughout the lifetime of a cow.

Key words: resilience, dairy cow, lactation stage, genetics

\section{INTRODUCTION}

Resilient cows are minimally affected in their functioning by environmental disturbances, such as pathogens or heat waves, or recover quickly (Colditz and Hine, 2016; Berghof et al., 2019b). A possibility to improve resilience is through genetic selection. Because resilience is not directly measurable, the use of resilience indicators has been explored (Elgersma et al., 2018; Poppe et al., 2020). These resilience indicators were derived from daily milk yield records, based on the hypothesis that milk yield of resilient cows will be minimally affected by disturbances, and if it is affected, it will quickly return to normal. Initially, the (natural log-transformed) variance of daily milk yield records was studied as a resilience indicator, where low variance was expected to indicate good resilience (Elgersma et al., 2018). However, later the variance of daily deviations from a fitted lactation curve was studied (LnVar), to remove effect of persistency of the lactation curve (Poppe et al., 2020). In addition, the lag- 1 autocorrelation $\left(\mathbf{r}_{\text {auto }}\right)$, and the skewness of daily yield deviations were studied. Low $\mathrm{r}_{\text {auto }}$, and a skewness around 0 were expected to indicate good resilience, because they indicate quick recovery and a symmetric distribution of milk yield deviations from an individual lactation curve due to 
absence of response to disturbances, respectively. Skewness was not a useful resilience indicator for breeding because of its low heritability (0.01) and unfavorable genetic correlations with some health traits. The LnVar and $r_{\text {auto }}$ were useful because they were heritable (0.21 and 0.09), and they were favorably genetically correlated with health and longevity. Similar resilience indicators were explored for body weight deviations in layer chickens (Berghof et al., 2019a), and feed intake in pigs (Putz et al., 2019). These studies showed that the LnVar of body weight and root mean square error of feed intake were useful as resilience indicators for breeding, because of their favorable genetic correlations with health and survival traits.

The resilience indicators explored by Poppe et al. (2020) were based on all daily milk yield records up to $350 \mathrm{~d}$ after calving in first lactation, which allows for breeding for improved resilience in first lactation. However, traits are often not genetically the same in different lactation stages or lactations. That holds not only for milk production itself (Brotherstone et al., 2000; Weller and Ezra, 2004), but also for traits related to resilience such as liability to clinical mastitis or tolerance to heat stress. For liability to clinical mastitis, genetic correlations between different days during lactation were between -0.14 and 1 (Heringstad et al., 2004; Carlén et al., 2009; Gernand and König, 2014). In addition, genetic correlations among the first 3 lactations for incidence of clinical mastitis were between 0.42 and 0.92 (Zwald et al., 2006; Bloemhof et al., 2009; Urioste et al., 2012). For heat tolerance of milk yield, genetic correlations among the first 3 lactations were between 0.72 and 0.79 (Aguilar et al., 2009). Based on these studies on susceptibility and tolerance to disturbances, we may hypothesize that resilience changes genetically within and between lactations.

If resilience changes genetically throughout and between lactations, breeding for the resilience indicators based on full first lactation proposed by Poppe et al. (2020) may not result in improved resilience throughout the entire lactation and throughout the entire life. Resilience indicators based on specific periods of the lactation may reflect resilience better than resilience indicators based on other periods, because vulnerability to disturbances may change throughout lactation. For example, incidence of multiple diseases is highest in early lactation (Ingvartsen et al., 2003; Gernand and König, 2014) and the effect of hot and humid weather on milk yield has been shown to be highest in mid- or late lactation (Maust et al., 1972; Aguilar et al., 2009; Santana et al., 2017). These observations suggest that fluctuations in daily milk yield at different lactation stages may be informative about different types of resilience. In addition, if the resilience indicators are genetically different traits in different lactations, an index of EBV for the resilience indicators based on different lactations may be needed to improve resilience throughout life.

The aim of this study was to estimate genetic parameters for the resilience indicators variance and autocorrelation of milk yield deviations based on 3 periods of lactation 1 and based on the first 3 full lactations, and to estimate genetic correlations among lactation periods and among lactations for these resilience indicators, and genetic correlations with health traits.

\section{MATERIALS AND METHODS}

In this study, we did a genetic analysis on 2 resilience indicators: the variance and lag-1 autocorrelation of milk yield deviations from individual lactation curves. The resilience indicators were based on all daily milk yield records of a cow in lactation 1 , lactation 2 , or lactation 3 , or on daily milk yield records from 3 different periods of lactation 1 . We will first describe data preparation, and we will then describe the genetic analysis.

\section{Data Preparation}

The initial data set contained 1,782,373,113 milk yield records of $1,120,550$ cows in different lactations obtained during single milkings by automatic milking systems (AMS) or conventional milking systems. The data set was obtained from Cooperation CRV and CRV BV (Arnhem, the Netherlands) and included records between 1998 and 2018. The data, as well as data preparation, were the same as in Poppe et al. (2020), but data preparation was extended to the second and third lactations. Data preparation was performed using the AWK programming language (Aho et al., 1988) and R (R v3.2.2; R Project for Statistical Computing, Vienna, Austria).

From the initial data set, only data from AMS and from lactations 1, 2, and 3 were extracted, and only cows were included that were herd-book registered and that were at least $87.5 \%$ Holstein Friesian. Furthermore, lactations were included only when age at calving was more than $640 \mathrm{~d}$ of age (lactation 1), $855 \mathrm{~d}$ (lactation 2 ), or 1,070 d (lactation 3). These numbers were based on minimum age at first calving and minimum interval between calvings used by Cooperation CRV (CRV, 2018a).

The milk yield records based on single AMS visits were first converted to daily milk yield records. Daily milk yield records after 350 DIM were removed. Then, for each cow, and for each lactation separately, a lactation curve was fitted using fourth order quantile polynomial regression, because this curve-fitting method gave 
the best resilience indicators among the 4 curve-fitting methods studied by Poppe et al. (2020):

$$
y_{t}=\beta_{0}+\beta_{1} \times t+\beta_{2} \times t^{2}+\beta_{3} \times t^{3}+\beta_{4} \times t^{4}+\varepsilon,
$$

where $y_{t}$ is the observed milk yield on DIM $t ; t^{n}$ are DIM to the power of $n$, where $n$ is $1,2,3$, or $4 ; \beta_{n}$ are regression coefficients describing the relationships between $t^{n}$ and $y_{t}$; and $\varepsilon$ is the error term. Quantile regression with a quantile of 0.7 was used to approximate the lactation curve in absence of disturbances. Disturbances mostly cause a reduction in milk yield and therefore the fitted curve was pushed upwards to the 0.7 quantile. As a consequence, negative deviations became larger and were expected to be more informative about resilience (Poppe et al., 2020). Curves were fitted using the quantreg package (Koenker, 2018) and the poly function in R.

After fitting the individual lactation curves for each cow and each lactation, the daily deviations from the fitted lactation curves were calculated. The deviations for d 1-10 and d 341-350 were removed because of poor fit of the lactation curve model at the extremes. First lactation was then split into 3 periods of $\sim 100 \mathrm{~d}$ each: d 11 to 110,111 to 210 , and 211 to 340 . The last period (d 211-340) is longer, but a substantial part of the cows was dried off before d $340(60 \%)$. To be included in the analyses, cows were required to have records available from the start of the lactation, and not more than $5 \%$ of daily deviations per lactation was allowed to be missing. The same standards were required for analysis of periods 2 and 3 of first lactation. For analysis of resilience indicators based on full lactations, at least 50 milk yield records were required per lactation. For analysis of resilience indicators based on the 3 lactation periods, at least 30 milk yield records were required per lactation period. As a consequence, it was possible that cows had resilience indicators based on full lactation and based on lactation period 1 , but not based on lactation periods 2 and 3, if a cow was, for example, culled at 70 DIM.

Natural log-transformed variance and $\mathrm{r}_{\text {auto }}$ of daily milk yield deviations (the resilience indicators), were then calculated for each cow separately for lactations 1,2 , and 3 , and for the 3 periods of lactation 1 . Note that LnVar is different from LnVar in Elgersma et al. (2018), which was the natural log-transformed variance of raw daily milk yield instead of daily deviations from a lactation curve. Low LnVar and $r_{\text {auto }}$ were expected to indicate good resilience because of few fluctuations in milk yield due to disturbances. In addition to LnVar and $r_{\text {auto }}$, average daily milk yield (ADMY) was calculated for each lactation and for each period of lactation
1. Calculating ADMY allowed us to adjust genetic correlations between the resilience indicators and health, longevity, fertility, and metabolic traits for milk yield level (see Genetic Analysis section). Furthermore, results of genetic analysis of ADMY could serve as a reference of how a well-known trait changed genetically over time.

Records of LnVar, $\mathrm{r}_{\text {auto }}$, and ADMY were set to missing if they deviated more than 4 standard deviations (SD) from the mean of that trait in that lactation or in that period of lactation 1. Finally, herd-year-season (HYS) of calving classes were made with 4 seasons (January-March, April-June, July-September, October-December). If a HYS class contained fewer than 5 cows in a certain lactation, the LnVar, $\mathrm{r}_{\text {auto }}$, and ADMY of those cows in that lactation were removed. The final number of records for LnVar, $\mathrm{r}_{\text {auto }}$, and ADMY used for analysis are shown in Table 1 . The number of cows with resilience indicators in lactation 1 is slightly different from the number of cows with resilience indicators analyzed in Poppe et al. (2020), because of a difference in data preparation related to fitting multiple lactation curves.

\section{Genetic Analysis}

Estimating Genetic Parameters. Genetic parameters were estimated using univariate, bivariate, and trivariate models. Because of the large amount of traits and genetic parameters to be estimated, many analyses were run. Table 2 summarizes for each genetic parameter which analysis was used and which traits were included. The analyses were performed using ASReml 4.1 (Gilmour et al., 2015), using a pedigree including 5 generations of ancestors. The following univariate mixed animal model was used:

$$
y_{i j k l}=H Y S_{i}+C A_{j}+L L_{k}+a_{l}+e_{i j k l}
$$

Table 1. The number of analyzed records for the resilience indicators LnVar (natural log-transformed variance of deviations from a lactation curve) and $r_{\text {auto }}$ (lag-1 autocorrelation of deviations from a lactation curve), and of ADMY (average daily milk yield, in $\mathrm{kg}$ ), based on different periods of lactation 1 or on different full lactations

\begin{tabular}{lrrr}
\hline Item & LnVar & $\mathrm{r}_{\text {auto }}$ & ADMY \\
\hline Lactation period 1 & 202,202 & 202,188 & 202,170 \\
Lactation period 2 & 194,776 & 194,736 & 194,777 \\
Lactation period 3 & 187,915 & 187,847 & 187,897 \\
Lactation 1 & 200,070 & 199,920 & 200,084 \\
Lactation 2 & 155,723 & 155,610 & 155,784 \\
Lactation 3 & 89,963 & 89,888 & 89,990 \\
\hline
\end{tabular}


where $y_{i j k l}$ was the observation on the analyzed trait, $H Y S_{i}$ was the fixed effect of herd-year-season of calving $i, C A_{j}$ was the fixed effect of calving age class $j, L L_{k}$ was the fixed effect of lactation length class $k, a_{l}$ was the random additive genetic effect of animal $l$ and $e_{i j k l}$ was a random error term. The calving age classes were based on age in months. The lactation length classes were based on the remaining number of days with data after removing the first and last 10 DIM (maximum 330 d). For full lactations, 7 classes of $40 \mathrm{~d}$ each were used (d 50-90, 91-130, 131-170, 171-210, 211-250, 251-290, 291-330). For periods of the lactation, the same classes were used, because the total length of the lactation may be informative about the resilience in the first, second, and third period of the lactation. An additional lactation length class (30-49 d) was included for period 1 of lactation 1, containing cows that had fewer than 50 lactation days, because we required resilience indicators based on lactation periods to be based on at least 30 records instead of 50. The following assumptions were made about the vector of random genetic effects $\mathbf{a}$ and the vector of residuals e: $\mathbf{a} \sim N\left(0, \mathbf{A} \sigma_{a}^{2}\right)$ and $\mathbf{e} \sim N\left(0, \mathbf{I} \sigma_{e}^{2}\right)$, where $\mathbf{A}$ is the additive genetic relationship matrix and $\mathbf{I}$ is the identity matrix, and $\sigma_{a}^{2}$ and $\sigma_{e}^{2}$ are the additive genetic variance and the residual variance.

The bivariate and trivariate models included the same fixed effects as the univariate model. The following assumptions were made about the additive genetic effects in the multivariate models:

$$
\left[\begin{array}{l}
\mathbf{a}_{1} \\
\mathbf{a}_{2}
\end{array}\right] \sim N\left[\left(\begin{array}{l}
0 \\
0
\end{array}\right), \mathbf{A} \otimes\left(\begin{array}{cc}
\sigma_{a_{1}}^{2} & \sigma_{a_{1} a_{2}} \\
\sigma_{a_{1} a_{2}} & \sigma_{a_{2}}^{2}
\end{array}\right)\right]
$$

and

$$
\left[\begin{array}{l}
\mathbf{a}_{1} \\
\mathbf{a}_{2} \\
\mathbf{a}_{3}
\end{array}\right] \sim N\left[\left(\begin{array}{l}
0 \\
0 \\
0
\end{array}\right), \mathbf{A} \otimes\left(\begin{array}{ccc}
\sigma_{a_{1}}^{2} & \sigma_{a_{1} a_{2}} & \sigma_{a_{1} a_{3}} \\
\sigma_{a_{1} a_{2}} & \sigma_{a_{2}}^{2} & \sigma_{a_{2} a_{3}} \\
\sigma_{a_{1} a_{3}} & \sigma_{a_{2} a_{3}} & \sigma_{a_{3}}^{2}
\end{array}\right)\right],
$$

where $\mathbf{a}_{i}$ is the vector with additive genetic effects for trait $i, \sigma_{a_{i}}^{2}$ is the additive genetic variance of trait $i$, and $\sigma_{a_{i} a_{j}}$ is the genetic covariance between trait $i$ and $j$. The following assumptions were made about the residuals in the multivariate models:

$$
\left[\begin{array}{l}
\mathbf{e}_{1} \\
\mathbf{e}_{2}
\end{array}\right] \sim N\left[\left(\begin{array}{l}
0 \\
0
\end{array}\right), \mathbf{I} \otimes\left(\begin{array}{cc}
\sigma_{e_{1}}^{2} & \sigma_{e_{1} e_{2}} \\
\sigma_{e_{1} e_{2}} & \sigma_{e_{2}}^{2}
\end{array}\right)\right]
$$

and

$$
\left[\begin{array}{l}
\mathbf{e}_{1} \\
\mathbf{e}_{2} \\
\mathbf{e}_{3}
\end{array}\right] \sim N\left[\left(\begin{array}{l}
0 \\
0 \\
0
\end{array}\right), \mathbf{I} \otimes\left(\begin{array}{ccc}
\sigma_{e_{1}}^{2} & \sigma_{e_{1} e_{2}} & \sigma_{e_{1} e_{3}} \\
\sigma_{e_{1} e_{2}} & \sigma_{e_{2}}^{2} & \sigma_{e_{2} e_{3}} \\
\sigma_{e_{1} e_{3}} & \sigma_{e_{2} e_{3}} & \sigma_{e_{3}}^{2}
\end{array}\right)\right],
$$

where $\mathbf{e}_{i}$ is the vector with residuals for trait $i, \sigma_{e_{i}}^{2}$ is the residual variance of trait $i$, and $\sigma_{e_{i} e_{j}}$ is the residual covariance between trait $i$ and $j$. Because of long computing time, the multivariate analyses were performed on 5 random subsets each containing approximately $20 \%$ of the cows. The subsets were made based on herd,

\begin{tabular}{|c|c|}
\hline Genetic parameters to be estimated & Analysis used \\
\hline $\begin{array}{l}\text { Variance components and heritabilities of each } \\
\text { trait in each full lactation }\end{array}$ & Trivariate analysis of the same trait recorded in the 3 full lactations \\
\hline $\begin{array}{l}\text { Genetic correlations between full lactation } 1 \text { and } \\
\text { the } 3 \text { lactation periods }\end{array}$ & $\begin{array}{l}\text { Bivariate analysis of the same trait in full lactation } 1 \text { and in each of the } 3 \text { lactation } \\
\text { periods }\end{array}$ \\
\hline Genetic correlations between lactation periods & Trivariate analysis of the same trait recorded in the 3 lactation periods \\
\hline $\begin{array}{l}\text { Genetic correlations of each trait with health, } \\
\text { longevity, fertility, and metabolic traits }\end{array}$ & $\begin{array}{l}\text { MACE procedure - bivariate analysis of de-regressed EBV of each trait in each lactation } \\
\text { period or full lactation and health, longevity, fertility and metabolic traits }\end{array}$ \\
\hline
\end{tabular}

Table 2. Summary of univariate and multivariate analyses used for estimating genetic parameters of 2 resilience indicators (natural logtransformed variance of deviations from a lactation curve and lag-1 autocorrelation of deviations from a lactation curve), and average daily milk yield ${ }^{1}$

${ }^{1}$ Trait = natural log-transformed variance of deviations from a lactation curve, lag-1 autocorrelation of deviations from a lactation curve, or average daily milk yield; $\mathrm{MACE}=$ multiple across-country evaluation. 
and weighted averages of the genetic correlations $(\bar{x})$ were estimated the same as in Poppe et al. (2020):

$$
\bar{x}=\frac{\sum_{i=1}^{5} w_{i} x_{i}}{\sum_{i=1}^{5} w_{i}},
$$

where $w_{i}$ was the number of animals in subset $i$ and $x_{i}$ was the estimated genetic correlation in subset $i$. Weighted SD of the genetic correlations $(s)$ were estimated as:

$$
s=\sqrt{\frac{\sum_{i=1}^{5} w_{i}\left(x_{i}-\bar{x}\right)^{2}}{\frac{4 \sum_{i=1}^{5} w_{i}}{5}}} .
$$

To calculate the standard error of the weighted average genetic correlations, the weighted SD were divided by the square root of 5, as in Poppe et al. (2020). For 2 trivariate analyses (among LnVar in the 3 full lactations and among $\mathrm{r}_{\text {auto }}$ in the 3 full lactations), one of the 5 subsets could not converge. Therefore, the weighted means of the genetic correlations from these analyses were based on 4 instead of 5 subsets $(\sim 230,000$ cows with a record in at least 1 of the lactations). Similarly, weighted averages of phenotypic correlations were calculated and can be found in the Appendix.

Genetic Correlations with Health, Longevity, Fertility, and Metabolic Traits. Genetic correlations were estimated between the resilience indicators and udder health, hoof health, ketosis resistance, longevity, fertility, BCS, and DMI. The purpose of these genetic correlations was to determine the value of LnVar and $\mathrm{r}_{\text {auto }}$ based on different lactations and periods of lactation 1 as a resilience indicator. Resilience is expected to be genetically related to good health, longevity, and fertility, and with a high BCS and DMI (Elgersma et al., 2018; Poppe et al., 2020). Instead of normal bivariate analyses, the multiple across-country evaluation (MACE) procedure was used to estimate the genetic correlations. The MACE procedure estimates genetic correlations between de-regressed EBV instead of phenotypes (Schaeffer, 1994; Klei and Weigel, 1998). Thus, the MACE procedure requires only EBV and their reliabilities as input, which eliminates the need for the data and the models underlying the health, longevity, fertility, and metabolic traits. For the resilience indicators, de-regressed sire EBV from the univariate analyses were used. For the health, longevity, fertility, and metabolic traits, de-regressed sire EBV from Co- operation CRV and CRV BV from the official run of April 2019 were used. The EBV were de-regressed to make their variance independent of their reliabilities and to take out the contribution of the parents (Larroque and Ducrocq, 1999). The EBV for udder health, hoof health, fertility, and DMI were an index of EBV from lactations 1, 2, and 3 (CRV, 2015; 2017; 2018c; 2019a). The EBV for productive longevity were based on survival per month (CRV, 2019b). The EBV for BCS (CRV , 2018b) were based on classifier observations in lactation 1. The EBV for ketosis resistance (Vosman et al., 2015) and official 305-d milk yield (CRV, 2018a) were based on data from lactations 1,2 , and 3 and were available for the 3 lactations separately. The MACE correlations with ketosis and official 305-d milk yield were, therefore, estimated per lactation (e.g., between LnVar in lactation 2 and ketosis in lactation 2). For the aforementioned EBV, a higher value means better health, longevity, or fertility, or a higher BCS, DMI, or milk yield.

Genetic Correlations Adjusted for Milk Yield. Considerable genetic correlations were shown between LnVar and ADMY, both in Poppe et al. (2020) and in this study. Because ADMY was also genetically related to health-related traits, it was desired to study genetic correlations between LnVar and the health, longevity, fertility, and metabolic traits at the same level of milk yield among cows. Therefore, partial genetic correlations between the resilience indicators and the health, longevity, fertility, and metabolic traits were calculated. The following formula was used:

$$
r_{x y}, z=\frac{r_{x y}-r_{x z} r_{y z}}{\sqrt{1-r_{x z}^{2}} \sqrt{1-r_{y z}^{2}}},
$$

where $r_{x y, z}$ is the partial genetic correlation between resilience indicator $x$ and health, longevity, fertility, or metabolic trait $y$, adjusted for ADMY $(z)$. Furthermore, $r_{x y}$ is de genetic correlation between resilience indicator $x$ and health, longevity, fertility, or metabolic trait $y$, $r_{x z}$ is the genetic correlation between resilience indicator $x$ and $\operatorname{ADMY}(z)$, and $r_{y z}$ is the genetic correlation between health, longevity, fertility, or metabolic trait $y$ and $\operatorname{ADMY}(z)$.

For the correlations between the resilience indicators and ADMY, genetic correlations were taken from the trivariate analyses among LnVar, $\mathrm{r}_{\text {auto }}$ and ADMY in each lactation period or full lactation. All other correlations were genetic correlations estimated using the MACE procedure. The same procedure was used in Poppe et al. (2020). 


\section{RESULTS}

\section{Descriptive Statistics of Resilience Indicators}

The mean of LnVar decreased from 1.54 in lactation period 1 to 1.00 in lactation period 3 , and the SD increased from 0.69 to 0.76 (Table 3). Furthermore, the mean of LnVar increased from 1.39 in lactation 1 to 1.83 in lactation 3, and the SD increased from 0.57 to 0.62 . The means and SD of $\mathrm{r}_{\text {auto }}$ were similar in the different periods of lactation 1 and the different lactations. The means ranged from 0.52 to 0.56 in both the periods of lactation 1 and the 3 full lactations, and the SD ranged from 0.23 to 0.24 in the periods of lactation 1 and from 0.18 to 0.19 in the 3 full lactations (Table 3 ). Similar to LnVar, the mean of ADMY decreased over the 3 periods of lactation 1 (from 29.81 to $22.90 \mathrm{~kg}$ ), and increased over lactations (from 26.60 to $33.53 \mathrm{~kg}$ ). In summary, LnVar and ADMY on average decreased within lactation 1 and increased over lactations, whereas $\mathrm{r}_{\text {auto }}$ was similar within and between lactations.

\section{Variance Components and Heritabilities of the Resilience Indicators}

Both the genetic and residual variance of LnVar increased from the first period of lactation 1 (11-110 d) to the last period (211-340 d): the genetic variance increased from 0.051 to 0.070 and the residual variance from 0.342 to 0.388 (Table 4). The heritability of LnVar was highest based on lactation period $3(0.15)$ and lowest based on lactation period $2(0.12)$. The genetic variance of LnVar was intermediate when based on the full first lactation (0.053) compared with different periods of lactation 1. However, the heritability of LnVar based on full lactation $1(0.20)$ was higher than the heritabilities of LnVar based on periods of lactation 1, due to a lower residual variance. The genetic variance of LnVar based on full lactations increased from 0.053 in lactation 1 to 0.057 in lactation 3 , whereas the residual variance increased from 0.21 to 0.25 (Table 4 ). The heritability decreased over lactations (0.20 to 0.19 ).

The genetic variance of $r_{\text {auto }}$ increased from the first period of lactation $1(0.0023)$ to the third period (0.0028). The residual variance was similar in the 3 periods of lactation 1 (0.044 to 0.046). The heritability of $r_{\text {auto }}$ was similar in the 3 periods of lactation, ranging from 0.049 in period 1 to 0.059 in period 3 . The genetic variance of $r_{\text {auto }}$ based on full lactation 1 (0.0025) was intermediate compared with the genetic variance of $r_{\text {auto }}$ based on the different periods of the lactation. However, the heritability of $r_{\text {auto }}$ based on the full lactation was higher (0.084) than based on the different periods, due to a lower residual variance. The genetic variance of $r_{\text {auto }}$ based on full lactations decreased from 0.0025 in lactation 1 to 0.0017 in lactation 3 , whereas the residual variance was similar across lactations (0.026 to 0.028 ; Table 4$)$. The heritability decreased over lactations (0.084 to 0.058).

The genetic variance of ADMY increased within lactation 1 from 5.80 in the first period to 9.37 in the last period, and the heritability increased from 0.32 to 0.45 (Table 4). The heritability of ADMY based on full lactation $1(0.45)$ was higher than the heritability of ADMY based on lactation period 1 (0.32), but similar to the heritability of ADMY based on lactation periods 2 and 3 (0.43 and 0.45). The genetic variance of ADMY was similar across full lactations (7.96 to 9.04), and

Table 3. Descriptive statistics of the resilience indicators LnVar (natural log-transformed variance of deviations from a lactation curve) and $\mathrm{r}_{\text {auto }}$ (lag-1 autocorrelation of deviations from a lactation curve), and of ADMY (average daily milk yield), based on different periods of lactation 1 or on different full lactations

\begin{tabular}{|c|c|c|c|c|c|}
\hline Trait & Moment of measurement & Mean & $\mathrm{SD}$ & Minimum & Maximum \\
\hline \multirow[t]{6}{*}{ LnVar } & Lactation period 1 & 1.54 & 0.69 & -1.21 & 4.28 \\
\hline & Lactation period 2 & 1.16 & 0.75 & -1.82 & 4.13 \\
\hline & Lactation period 3 & 1.00 & 0.76 & -2.01 & 4.01 \\
\hline & Lactation 1 & 1.39 & 0.57 & -0.89 & 3.69 \\
\hline & Lactation 2 & 1.64 & 0.60 & -0.78 & 4.06 \\
\hline & Lactation 3 & 1.83 & 0.62 & -0.62 & 4.30 \\
\hline \multirow{6}{*}{$\mathrm{r}_{\text {auto }}$} & Lactation period 1 & 0.52 & 0.23 & -0.42 & 0.99 \\
\hline & Lactation period 2 & 0.54 & 0.24 & -0.41 & 0.99 \\
\hline & Lactation period 3 & 0.54 & 0.23 & -0.40 & 0.98 \\
\hline & Lactation 1 & 0.55 & 0.19 & -0.22 & 0.98 \\
\hline & Lactation 2 & 0.56 & 0.18 & -0.18 & 0.99 \\
\hline & Lactation 3 & 0.55 & 0.19 & -0.19 & 0.99 \\
\hline \multirow[t]{6}{*}{ ADMY } & Lactation period 1 & 29.81 & 5.24 & 8.81 & 50.54 \\
\hline & Lactation period 2 & 27.18 & 5.60 & 5.00 & 49.13 \\
\hline & Lactation period 3 & 22.90 & 5.41 & 3.48 & 44.57 \\
\hline & Lactation 1 & 26.60 & 4.99 & 6.98 & 46.49 \\
\hline & Lactation 2 & 31.33 & 5.85 & 7.95 & 54.62 \\
\hline & Lactation 3 & 33.53 & 6.05 & 9.27 & 57.37 \\
\hline
\end{tabular}


the residual variance increased over lactations (9.73 to 17.66). The heritability decreased over lactations $(0.45$ to 0.34 ). In summary, the genetic variance and heritability of LnVar and ADMY generally increased within lactation 1 , whereas it remained similar for $\mathrm{r}_{\text {auto }}$. However, the genetic variance and heritability decreased from lactation 1 to 3 for LnVar, $\mathrm{r}_{\text {auto }}$, and ADMY.

\section{Genetic Correlations Between Lactation Periods and Full Lactations}

Strong genetic correlations were observed between different lactation periods or full lactations for LnVar, $\mathrm{r}_{\text {auto }}$, and ADMY (Tables 5 and 6). The genetic correlations between full lactation 1 and the different periods of lactation 1 ranged from 0.90 to 0.99 (Table 5). Note that these are strong because of the part-whole relationship. For each trait, the first or last period of lactation 1 had the weakest genetic correlation with the full first lactation, whereas the second period had the strongest genetic correlation with the full lactation. Within lactation 1 , the genetic correlation between period 2 and 3 was strongest for all traits (0.96 to 0.97 ), whereas the genetic correlation between period 1 and 3 was weakest (0.65 to 0.81$)$. For each trait, the genetic correlation between lactation 2 and 3 was strongest (0.95 to 0.99; Table 6), and the genetic correlation between lactation 1 and 3 was weakest ( 0.71 to 0.91 ). The lowest genetic correlation was always for $\mathrm{r}_{\text {auto }}$, whereas the genetic correlations for LnVar and ADMY were more similar. In summary, basing a resilience indicator or ADMY on different periods of lactation 1 or on different lactations, resulted in genetically similar traits, but the genetic correlations decreased when the periods within lactation or full lactations were further apart in time.

\section{Genetic Correlations Among LnVar, $r_{\text {auto, }}$ and ADMY}

The genetic correlation between LnVar and $r_{\text {auto }}$ was weak based on all 3 lactation periods and based on all full lactations ( -0.13 to 0.02 ; Table 7$)$. Therefore, LnVar and $r_{\text {auto }}$ were genetically independent traits, irrespective of when they were measured. The genetic correlation between LnVar and ADMY was positive and strong based on all different lactation periods and based on all full lactations (0.72 to 0.81; Table 7), which means that cows with genetically a high milk yield tended to have a high variability in milk yield. The genetic correlations between $\mathrm{r}_{\text {auto }}$ and ADMY were also mostly positive ( -0.04 to 0.28$)$, but weaker than the genetic correlations between LnVar and ADMY. The genetic correlations between $r_{\text {auto }}$ and ADMY differed considerably between different lactation periods and different lactations. In summary, LnVar and $r_{\text {auto }}$ were genetically independent traits based on all periods of lactation 1 and all lactations, and both traits were mostly positively correlated with ADMY, with strong genetic correlations between LnVar and ADMY.

Table 4. Heritability $\left(\mathrm{h}^{2}\right)$, additive genetic variance $\left(\sigma_{a}^{2}\right)$ and residual variance $\left(\sigma_{e}^{2}\right)$ of the resilience indicators LnVar (natural log-transformed variance of deviations from a lactation curve) and $\mathrm{r}_{\text {auto }}$ (lag-1 autocorrelation of deviations from a lactation curve), and of average daily milk yield (ADMY), based on different periods of lactation 1 or on different full lactations ${ }^{1}$

\begin{tabular}{|c|c|c|c|c|}
\hline Trait & Moment of measurement & $\mathrm{h}^{2}$ & $\sigma_{a}^{2}$ & $\sigma_{e}^{2}$ \\
\hline \multirow[t]{6}{*}{ LnVar } & Lactation period 1 & $0.13(0.0074)$ & $0.051(0.0031)$ & $0.34(0.0025)$ \\
\hline & Lactation period 2 & $0.12(0.0065)$ & $0.054(0.0032)$ & $0.40(0.0026)$ \\
\hline & Lactation period 3 & $0.15(0.0094)$ & $0.070(0.0046)$ & $0.39(0.0035)$ \\
\hline & Lactation $1_{*}^{*}$ & $0.20(0.0040)$ & $0.053(0.0010)$ & $0.21(0.0015)$ \\
\hline & Lactation $2^{*}$ & $0.18(0.0066)$ & $0.053(0.0019)$ & $0.24(0.0019)$ \\
\hline & Lactation $3^{*}$ & $0.19(0.010)$ & $0.057(0.0033)$ & $0.25(0.0029)$ \\
\hline \multirow{6}{*}{$\mathrm{r}_{\text {auto }}$} & Lactation period 1 & $0.049(0.0027)$ & $0.0023(0.00012)$ & $0.044(0.00037)$ \\
\hline & Lactation period 2 & $0.050(0.0024)$ & $0.0024(0.00011)$ & $0.046(0.00033)$ \\
\hline & Lactation period 3 & $0.059(0.0014)$ & $0.0028(0.000062)$ & $0.044(0.00033)$ \\
\hline & Lactation $1^{*}$ & $0.084(0.0021)$ & $0.0025(0.000069)$ & $0.028(0.00017)$ \\
\hline & Lactation $2^{*}$ & $0.073(0.0062)$ & $0.0021(0.00017)$ & $0.026(0.00030)$ \\
\hline & Lactation $3^{*}$ & $0.058(0.0083)$ & $0.0017(0.00027)$ & $0.028(0.00017)$ \\
\hline \multirow[t]{6}{*}{ ADMY } & Lactation period 1 & $0.32(0.0033)$ & $5.80(0.082)$ & $12.50(0.086)$ \\
\hline & Lactation period 2 & $0.43(0.0088)$ & $9.24(0.21)$ & $12.38(0.18)$ \\
\hline & Lactation period 3 & $0.45(0.012)$ & $9.37(0.31)$ & $11.63(0.19)$ \\
\hline & Lactation 1 & $0.45(0.0050)$ & $7.96(0.10)$ & $9.73(0.085)$ \\
\hline & Lactation 2 & $0.37(0.0050)$ & $9.04(0.13)$ & $15.31(0.12)$ \\
\hline & Lactation 3 & $0.34(0.0033)$ & $9.04(0.092)$ & $17.66(0.17)$ \\
\hline
\end{tabular}

${ }^{1}$ Estimates are weighted means of trivariate analyses of 5 subsets of the data; empirical SE between parentheses. * indicates weighted mean of variance components of 4 subsets of complete data set instead of 5 . 
Table 5. Genetic correlations among periods 1, 2, and 3 of the first lactation and genetic correlations between the 3 lactation periods and the full first lactation for the resilience indicators LnVar (natural log-transformed variance of deviations from a lactation curve) and $\mathrm{r}_{\text {auto }}$ (lag-1 autocorrelation of deviations from a lactation curve), and for average daily milk yield (ADMY) ${ }^{1}$

\begin{tabular}{llll}
\hline Item & LnVar & \multicolumn{1}{c}{$\mathrm{r}_{\text {auto }}$} & \multicolumn{1}{c}{ ADMY } \\
\hline Lactation period 1 and 2 & $0.88(0.012)$ & $0.82(0.014)$ & $0.90(0.0063)$ \\
Lactation period 1 and 3 & $0.81(0.017)$ & $0.65(0.029)$ & $0.80(0.012)$ \\
Lactation period 2 and 3 & $0.97(0.0067)$ & $0.96(0.017)$ & $0.96(0.0024)$ \\
Lactation period 1 and full lactation 1 & $0.95(0.0053)$ & $0.91(0.011)$ & $0.93(0.0037)$ \\
Lactation period 2 and full lactation 1 & $0.97(0.0031)$ & $0.98(0.0035)$ & $0.99(0.00045)$ \\
Lactation period 3 and full lactation 1 & $0.95(0.0063)$ & $0.90(0.010)$ & $0.97(0.0024)$ \\
\hline
\end{tabular}

${ }^{1}$ Genetic correlations are weighted means of trivariate analyses of 5 subsets of the data; empirical SE are between parentheses.

\section{Genetic Correlations with Health, Longevity, Fertility, and Metabolic Traits}

The LnVar based on all lactation periods and on all full lactations had negative genetic correlations $(-0.04$ to -0.48$)$ with the health, longevity, fertility, and metabolic traits except DMI (Table 8). The genetic correlations between LnVar and DMI were positive and ranged from 0.13 to 0.35 . These genetic correlations mean that low LnVar was genetically related to good health, longevity, and fertility, and a high BCS and low DMI (Table 8). However, LnVar had strong genetic correlations with ADMY (0.72 to 0.81; Table 7), and ADMY also had substantial genetic correlations with some of the health, longevity, fertility, and metabolic traits $(-0.38$ to 0.66 ; Table 8$)$. The genetic correlations with ADMY were often in the same direction as the ones for LnVar. Therefore, the partial genetic correlations, adjusted for ADMY (Table 9) are more informative about the associations between LnVar and the health, longevity, fertility, and metabolic traits, independent of ADMY.

Almost all partial genetic correlations between LnVar and the health, longevity, fertility, and metabolic traits, except for the correlations with DMI, were in the same direction as the original genetic correlations

Table 6. Genetic correlations between lactations 1,2 and 3 for the resilience indicators LnVar (natural log-transformed variance of deviations from a lactation curve) and $\mathrm{r}_{\text {auto }}$ (lag-1 autocorrelation of deviations from a lactation curve), and for average daily milk yield $(\mathrm{ADMY})^{1}$

\begin{tabular}{llcc}
\hline Item & LnVar & $\mathrm{r}_{\text {auto }}$ & ADMY \\
\hline Lactation 1 and 2 & $0.94(0.0074)$ & $0.83(0.018)$ & $0.89(0.0065)$ \\
Lactation 1 and 3 & $0.91(0.017)$ & $0.71(0.021)$ & $0.89(0.0063)$ \\
Lactation 2 and 3 & $0.99(0.012)$ & $0.95(0.021)$ & $0.98(0.0020)$ \\
\hline
\end{tabular}

${ }^{1}$ Genetic correlations are weighted means of trivariate analyses of 5 subsets of the data; empirical SE are between parentheses. LnVar and $r_{\text {auto }}$ are weighted mean of genetic correlations of 4 subsets of complete data set instead of 5 . between LnVar and these traits ( -0.51 to 0.02; Table 9 ). Most of these partial correlations were similar or weaker than the original genetic correlations. An exception is the partial genetic correlations with udder health, longevity, and BCS in lactations 2 and $3(-0.34$ to -0.51 ), which were considerably stronger than the original genetic correlations $(-0.15$ to -0.33$)$. The partial genetic correlations suggest that among cows with genetically the same level of milk yield, the cows with a less variable milk yield (low LnVar) tended to have better health, longevity, and fertility, and a higher BCS than cows with a more variable milk yield. Strikingly, the partial genetic correlations of LnVar with DMI were negative $(-0.30$ to -0.59$)$, whereas the original genetic correlations were positive, which means that among cows with genetically the same level of milk yield, the cows with less variable milk yield (low LnVar) tended to eat more than cows with more variable milk yield.

The partial genetic correlations between LnVar and the health, longevity, fertility, and metabolic traits were often comparable between the lactation periods. However, these partial correlations were weaker than or similar to the partial genetic correlations for LnVar based on full first lactation. The partial genetic correlations between LnVar and udder health and longevity were considerably stronger based on lactations 2 and $3(-0.42$ to -0.51$)$ than based on lactation $1(-0.30$ to -0.31 ). In summary, at a genetically equal level of milk yield, low LnVar was genetically strongest related with health, longevity, and fertility when based on full lactations, and genetic correlations with udder health and longevity increased from lactation 1 to lactation 2 and 3 .

In most lactations and lactation periods, low $\mathrm{r}_{\text {auto }}$ was genetically related to good udder health, hoof health, ketosis resistance, and fertility, and a high BCS and DMI. However, most correlations were weak $\left(\mathrm{r}_{\mathrm{g}}\right.$ from -0.27 to 0.06 ; Table 8 ). Due to the weak genetic correlations between $\mathrm{r}_{\text {auto }}$ and ADMY ( -0.04 to 0.28; Table 
Table 7. Genetic correlations among LnVar (natural log-transformed variance of deviations from a lactation curve), $\mathrm{r}_{\text {auto }}$ (lag-1 autocorrelation of deviations from a lactation curve), and ADMY (average daily milk yield) for periods 1,2 , and 3 of the first lactation, and for full lactations 1,2 , and $3^{1}$

\begin{tabular}{lccc}
\hline Item & LnVar and $\mathrm{r}_{\text {auto }}$ & LnVar and ADMY & $\mathrm{r}_{\text {auto }}$ and ADMY \\
\hline Lactation period 1 & $0.023(0.031)$ & $0.74(0.018)$ & $0.28(0.033)$ \\
Lactation period 2 & $-0.13(0.019)$ & $0.79(0.013)$ & $-0.041(0.011)$ \\
Lactation period 3 & $-0.10(0.034)$ & $0.80(0.015)$ & $0.17(0.036)$ \\
Lactation 1 & $-0.016(0.054)$ & $0.76(0.021)$ & $0.15(0.050)$ \\
Lactation 2 & $-0.030(0.051)$ & $0.81(0.0078)$ & $0.081(0.036)$ \\
Lactation 3 & $-0.024(0.11)$ & $0.72(0.025)$ & $0.024(0.052)$ \\
\hline
\end{tabular}

${ }^{1}$ Genetic correlations are weighted means of trivariate analyses of 5 subsets of the data; empirical SE are between parentheses.

7), the partial genetic correlations (Table 9) with the health, longevity, fertility, and metabolic traits were similar to the original genetic correlations. The only exceptions were the partial correlations between DMI and $r_{\text {auto }}$ based on lactation period 1 and full lactation $1(-0.39$ and -0.19 ; Table 9$)$, which were considerably stronger than the original correlations $(-0.14$ and -0.04; Table 8). All health, longevity, fertility, and metabolic traits had stronger genetic correlations with $\mathrm{r}_{\text {auto }}$ based on lactation period $1(-0.26$ to -0.06$)$ than with $r_{\text {auto }}$ based on full lactation 1 or based on lactation periods 2 or 3 ( -0.21 to 0.06 ; Table 8$)$. Moreover, $\mathrm{r}_{\text {auto }}$ based on lactation periods 2 and 3 were not favorably correlated with all health, longevity, fertility, and metabolic traits, whereas $\mathrm{r}_{\text {auto }}$ based on lactation period 1 and full lactation 1 were. Furthermore, the genetic correlations between $\mathrm{r}_{\text {auto }}$ and the health, longevity, fertility, and metabolic traits were similar over lactations. However, the genetic correlation between $r_{\text {auto }}$ and udder health differed substantially between lactations, with the strongest correlation for lactation $3(-0.27)$ and the weakest for lactation $2(-0.10)$. In summary, low $\mathrm{r}_{\text {auto }}$ was favorably, but mostly weakly, genetically correlated with health, longevity, and fertility based on lactation period 1 and based on most full lactations, and correlations were in most cases strongest for $r_{\text {auto }}$ based on lactation period 1.

\section{DISCUSSION}

Genetic change within and between lactations was studied for 2 resilience indicators, LnVar and $r_{\text {auto }}$. Low

Table 8. Genetic correlations of LnVar (natural log-transformed variance of deviations from a lactation curve), $\mathrm{r}_{\text {auto }}$ (lag-1 autocorrelation of deviations from a lactation curve), and ADMY (average daily milk yield) based on periods 1, 2, and 3 of the first lactation and full lactations 1,2 , and 3 with health, functional, metabolic, and production traits ${ }^{1}$

Health, functional, and metabolic traits ${ }^{2}$

\begin{tabular}{|c|c|c|c|c|c|c|c|c|c|}
\hline \multirow{2}{*}{\multicolumn{2}{|c|}{ Resilience indicator }} & \multirow{2}{*}{$\begin{array}{c}\mathrm{UH} \\
-0.30\end{array}$} & & & & & & & \\
\hline & & & $\begin{array}{c}\mathrm{HH} \\
-0.10\end{array}$ & $\frac{\mathrm{KET}}{-0.48}$ & $\frac{\mathrm{LON}}{-0.18}$ & $\begin{array}{c}\text { FER } \\
-0.36\end{array}$ & $\begin{array}{c}\text { BCS } \\
-0.42\end{array}$ & $\begin{array}{r}\text { DMI } \\
0.13\end{array}$ & $\begin{array}{r}\mathrm{OMY} \\
0.50\end{array}$ \\
\hline & Lactation period 2 & -0.28 & -0.19 & -0.44 & -0.11 & -0.36 & -0.38 & 0.21 & 0.62 \\
\hline & Lactation period 3 & -0.21 & -0.16 & -0.40 & -0.04 & -0.35 & -0.29 & 0.35 & 0.69 \\
\hline & Lactation 2 & -0.31 & -0.09 & -0.41 & -0.15 & -0.25 & -0.26 & 0.34 & 0.61 \\
\hline & Lactation 3 & -0.33 & -0.12 & -0.41 & -0.17 & -0.25 & -0.22 & 0.22 & 0.48 \\
\hline \multirow{4}{*}{$\mathrm{r}_{\text {auto }}$} & Lactation period 1 & -0.24 & -0.08 & -0.22 & -0.06 & -0.19 & -0.26 & -0.14 & 0.15 \\
\hline & Lactation 1 & -0.21 & -0.05 & -0.15 & -0.03 & -0.11 & -0.12 & -0.04 & 0.12 \\
\hline & Lactation 2 & -0.10 & -0.04 & -0.18 & 0.05 & -0.08 & -0.02 & 0.05 & 0.13 \\
\hline & Lactation 3 & -0.27 & -0.01 & -0.17 & -0.04 & -0.03 & -0.03 & -0.05 & 0.01 \\
\hline \multirow{4}{*}{ ADMY } & Lactation period 1 & -0.23 & -0.16 & -0.36 & -0.04 & -0.34 & -0.29 & 0.59 & 0.85 \\
\hline & Lactation period 2 & -0.15 & -0.13 & -0.38 & 0.08 & -0.33 & -0.19 & 0.63 & 0.93 \\
\hline & Lactation period 3 & -0.08 & -0.12 & -0.35 & 0.14 & -0.34 & -0.17 & 0.66 & 0.90 \\
\hline & Lactation 1 & -0.16 & -0.14 & -0.38 & 0.06 & -0.35 & -0.22 & 0.66 & 0.95 \\
\hline
\end{tabular}

${ }^{1}$ Genetic correlations were estimated using the multiple across-country evaluation (MACE) procedure; SE are not calculated in the MACE procedure.

${ }^{2} \mathrm{UH}=$ udder health; $\mathrm{HH}=$ hoof health; KET $=$ ketosis resistance; LON = longevity; FER = fertility; OMY = official milk yield in 305 d. 
Table 9. Partial genetic correlations of the resilience indicators LnVar (natural log-transformed variance of deviations from a lactation curve) and $\mathrm{r}_{\text {auto }}$ (lag-1 autocorrelation of deviations from a lactation curve) based on periods 1,2, and 3 of the first lactation and full lactations 1,2, and 3 with health, functional, and metabolic traits adjusted for average daily milk yield ${ }^{1}$

\begin{tabular}{|c|c|c|c|c|c|c|c|c|}
\hline \multirow{2}{*}{\multicolumn{2}{|c|}{ Resilience indicator }} & \multicolumn{7}{|c|}{ Health, functional, and metabolic traits ${ }^{2}$} \\
\hline & & $\mathrm{UH}$ & $\mathrm{HH}$ & KET & $\mathrm{LON}$ & FER & BCS & DMI \\
\hline \multirow[t]{6}{*}{ LnVar } & Lactation period 1 & -0.19 & 0.02 & -0.34 & -0.23 & -0.17 & -0.32 & -0.56 \\
\hline & Lactation period 2 & -0.26 & -0.14 & -0.25 & -0.28 & -0.17 & -0.38 & -0.59 \\
\hline & Lactation period 3 & -0.23 & -0.11 & -0.22 & -0.25 & -0.14 & -0.27 & -0.41 \\
\hline & Lactation 1 & -0.31 & -0.05 & -0.32 & -0.30 & -0.22 & -0.38 & -0.56 \\
\hline & Lactation 2 & -0.51 & -0.01 & -0.43 & -0.45 & -0.14 & -0.41 & -0.44 \\
\hline & Lactation 3 & -0.51 & -0.15 & -0.34 & -0.42 & -0.13 & -0.34 & -0.30 \\
\hline \multirow[t]{6}{*}{$r_{\text {auto }}$} & Lactation period 1 & -0.18 & -0.03 & -0.13 & -0.05 & -0.11 & -0.19 & -0.39 \\
\hline & Lactation period 2 & -0.17 & -0.04 & -0.10 & 0.02 & 0.02 & -0.10 & -0.04 \\
\hline & Lactation period 3 & -0.07 & 0.04 & -0.01 & 0.04 & 0.05 & 0.04 & -0.18 \\
\hline & Lactation 1 & -0.19 & -0.03 & -0.11 & -0.04 & -0.06 & -0.09 & -0.19 \\
\hline & Lactation 2 & -0.10 & -0.03 & -0.17 & 0.04 & -0.07 & -0.02 & 0.00 \\
\hline & Lactation 3 & -0.27 & -0.01 & -0.17 & -0.05 & -0.03 & -0.03 & -0.07 \\
\hline
\end{tabular}

${ }^{1} \mathrm{SE}$ are not calculated in the multiple across-country evaluation (MACE) procedure.

${ }^{2} \mathrm{UH}=$ udder health; $\mathrm{HH}=$ hoof health; KET = ketosis resistance; LON = longevity; FER = fertility.

LnVar and low $r_{\text {auto }}$ were expected to indicate good resilience, which means low vulnerability to disturbances and quick recovery (Berghof et al., 2019b; Poppe et al., 2020). Genetic correlations of the resilience indicators between lactation periods and lactations were strong but not 1 , which suggests that the resilience indicators were genetically similar but not the same traits throughout life. As expected, the estimated genetic parameters for resilience indicators based on full lactation 1 were almost the same as those in Poppe et al. (2020), because of using the same data set and model. Note that the genetic parameters for LnVar in this study were different from the genetic parameters for LnVar in Elgersma et al. (2018), which was defined differently. LnVar in Elgersma et al. (2018) was the natural logtransformed variance of raw daily milk yield instead of daily deviations, and was therefore defined the same as the raw variance in Poppe et al. (2020). However, the difference in genetic parameters between LnVar in Elgersma et al. (2018) and LnVar in the current study is probably mainly due to a difference in the model and not due to the different definition. The raw variance (Poppe et al., 2020) was analyzed with the same model as LnVar in this study and had similar genetic parameters. Nevertheless, LnVar as defined in this study is believed to be more closely related to resilience than raw variance, because it excludes the influence of the shape of the lactation curve (Poppe et al., 2020). We will first discuss genetic change of the resilience indicators between periods of the first lactation, and we will then discuss changes of the resilience indicators between lactations. Finally, we will discuss how our results can be used to improve resilience throughout life.

\section{Genetic Change of the Resilience Indicators Within Lactation}

For both LnVar and $r_{\text {auto }}$, the genetic correlation between lactation period 2 and 3 (DIM 111-210 and DIM 211-340, respectively) was considerably stronger than the genetic correlations between lactation period 1 (DIM 11-110) and the other 2 periods. These correlations suggest that the resilience indicators are partly determined by different genes in early lactation than in the rest of the lactation. It is commonly observed that traits in early lactation are different than the rest of lactation, such as fat and protein yield (Jamrozik and Schaeffer, 1997), liability to clinical mastitis (Chang et al., 2004; Heringstad et al., 2004; Negussie et al., 2008), SCC and SCS (Haile-Mariam et al., 2001; Mrode and Swanson, 2003; Elsaid et al., 2011), liability to hoof problems (Alkhoder et al., 2010; Gernand et al., 2013), and traits related to energy balance (Koenen and Veerkamp, 1998; Manzanilla Pech et al., 2014; Harder et al., 2020).

An explanation for the genetic difference between the resilience indicators in early lactation and in the rest of the lactation is that increased LnVar and $r_{\text {auto }}$ are caused by different disturbances in different periods of the lactation. Elevated LnVar or $\mathrm{r}_{\text {auto }}$ due to diseases may be more abundant in the first period of the lactation than in the other periods, because incidence of multiple diseases has been shown to be highest in early lactation (Ingvartsen et al., 2003; Gernand and König, 2014). Elevated LnVar or $r_{\text {auto }}$ due to heat stress may be more abundant in periods 2 and 3 of the lactation than in period 1, because the effect of heat stress on milk 
yield has been shown to be highest in mid- or late lactation (Maust et al., 1972; Aguilar et al., 2009; Santana et al., 2017). Different genes may be involved in handling different disturbances, explaining the genetic difference between the resilience indicators in lactation period 1 and the other lactation periods. A similar explanation has been given for the genetic difference of mean SCC between early lactation and the rest of the lactation. Elevated SCC in early lactation is mainly caused by environmental pathogens that cause a spike in SCC, such as Escherichia coli, whereas elevated SCC in later lactation is mainly caused by infections that result in a more stable elevation of SCC, such as Staphyloccocus aureus (Detilleux et al., 1997; Haile-Mariam et al., 2001; De Haas et al., 2004). In summary, the genetic difference between resilience indicators in early and later lactation may be explained by differences in vulnerability to different disturbances, which is similar to SCC.

The heritability of both LnVar and $\mathrm{r}_{\text {auto }}$ was comparable between lactation period 1 and 2 and increased only slightly in lactation period 3, which is different from results from literature on disease traits, SCC, and milk yield. Heritability of disease traits is often highest in early lactation compared with the remainder of the lactation (Chang et al., 2004; Heringstad et al., 2004; Gernand et al., 2013). On the contrary, heritability of mean SCC and milk yield is often lowest in early lactation due to a higher influence of environmental factors, such as diseases, resulting in a high residual variance (Haile-Mariam et al., 2001; Mrode and Swanson, 2003; Elsaid et al., 2011; Bohlouli et al., 2013). LnVar and $\mathrm{r}_{\text {auto }}$ showed genetic variation across the whole lactation and heritabilities were similar across lactation, which may suggest that disturbances occur and lead to genetic variation in resilience throughout the entire lactation.

The genetic correlations between lactation periods for LnVar were stronger than those for $r_{\text {auto }}$, and were similar to the ones for ADMY. However, because of the strong genetic correlations between LnVar and ADMY, influence of milk yield level on the genetic correlations between lactation periods for LnVar may be large. Partial genetic correlations between LnVar based on different lactation periods, adjusted for genetic correlations with ADMY based on full lactation, were 0.75 between lactation periods 1 and 2, 0.59 between lactation periods 1 and 3, and 0.92 between lactation periods 2 and 3 (data not shown). These partial correlations are lower than the original correlations (Table 5) and are closer to the genetic correlations between lactation periods of $r_{\text {auto }}$ (Table 5). The partial genetic correlations between LnVar based on different lactation periods and the genetic correlations between $r_{\text {auto }}$ based on different lactation periods suggest that resilience changes more throughout lactation than milk yield.

\section{Genetic Change of the Resilience Indicators Between Lactations}

For both LnVar and $\mathrm{r}_{\text {auto }}$, the genetic correlations between lactations decreased as lactations were further apart in time, and genetic correlations were strongest between lactations 2 and 3 .

It is commonly observed that genetic correlations are stronger between lactations that are closer in time than between lactations that are further apart, including correlations for milk, fat, and protein yield (Weller and Ezra, 2004), clinical mastitis (Carlén et al., 2004; Heringstad et al., 2004; Urioste et al., 2012), and SCS or SCC (Haile-Mariam et al., 2001; Carlén et al., 2004; Weller and Ezra, 2004). An explanation for the genetic difference in the resilience indicators between lactation 1 and the other lactations is that primiparous cows are different from multiparous cows in terms of nutrient partitioning and energy mobilization. Primiparous cows have to partition more of their nutrients to growth than multiparous cows, and have a lower milk yield (Wathes et al., 2007; Whittemore, 2009). Furthermore, primiparous cows mobilize less body energy than multiparous cows (Friggens et al., 2007). Therefore, different genes may be involved in partitioning energy to handling disturbances (being resilient) in first lactation than in later lactations.

The same resilience indicator recorded in different lactations could be considered a repeated trait instead of as different traits. Estimating repeatability using a repeatability model would be interesting. However, a multitrait model is preferred over a repeatability model, because a repeatability model assumes the trait to be genetically identical across lactations (Meyer and Hill, 1997), which was not true for the resilience indicators. Nevertheless, the phenotypic correlations between lactations (Appendix Table A2) provide an indication of repeatability (Barker and Robertson, 1966), and suggest that $r_{\text {auto }}$ has lower repeatability $\left(r_{p}\right.$ of $\left.0.16-0.28\right)$ than LnVar $\left(\mathrm{r}_{\mathrm{p}}\right.$ of $\left.0.29-0.36\right)$, and both have lower repeatability than ADMY ( $\mathrm{r}_{\mathrm{p}}$ of $\left.0.53-0.57\right)$.

\section{Genetic Improvement of Resilience to Maximize Trouble-Free Lifetime Production}

The below unity genetic correlations between lactation periods for LnVar and $r_{\text {auto }}$ may suggest that genetic selection should focus on periods of the lactation that are most informative about resilience instead of on full lactation. However, for LnVar it is unlikely that a particular period of the lactation is more informative about resilience than full lactation. The partial genetic correlations between LnVar and the health traits and longevity were stronger when based on full lactation 
than when based on one of the lactation periods, or they were similar. Therefore, to improve resilience using LnVar, data from the full lactation is recommended to be used. However, $r_{\text {auto }}$ was only favorably correlated with all health traits and longevity when based on lactation period 1 or full lactation and not when based on the other lactation periods. Although the genetic correlations with health traits and longevity were stronger in lactation period 1 than in the full lactation, selection on $r_{\text {auto }}$ based on full lactation is recommended. The heritability of $r_{\text {auto }}$ was higher based on full lactation than based on lactation period 1 and the genetic correlation between them was strong due to their part-whole relationship (0.91). Therefore, if we would assume mass selection on $r_{\text {auto }}$, the accuracy of direct selection on $\mathrm{r}_{\text {auto }}$ in lactation period 1 would be lower (0.23) than the accuracy of indirect selection on $\mathrm{r}_{\text {auto }}$ in lactation period 1 using $\mathrm{r}_{\text {auto }}$ in full lactation (0.27). Therefore, indirect selection using $r_{\text {auto }}$ based on full lactation would be more effective than direct selection on $r_{\text {auto }}$ based on lactation period 1 .

Both LnVar and $r_{\text {auto }}$ were genetically similar traits in different lactations, but genetic correlations deviated from unity. Therefore, to improve resilience not only in first lactation, but also later in life, records from all 3 lactations are recommended to be used. A similar recommendation has been given for other traits, such as clinical mastitis and SCC (Banos and Shook, 1990; Pösö and Mäntysaari, 1996; Carlén et al., 2004), fertility traits (Muuttoranta et al., 2019), and milk yield (Banos and Shook, 1990; Pösö and Mäntysaari, 1996). Moreover, for LnVar partial genetic correlations with the health traits were stronger in later lactations than in lactation 1 . Therefore, composing a resilience index of LnVar based on not only lactation 1, but also lactation 2 and 3 , is expected to increase the correlated response in the health traits, which is desired from a resilience perspective. Due to the weak genetic correlations of $r_{\text {auto }}$ with health traits, the added value of $\mathrm{r}_{\text {auto }}$ as a resilience indicator is questionable and further research is needed.

In practice, the index for resilience should be incorporated into the already existing total merit index containing other important traits, such as yield, longevity, fertility, and health traits (Berghof et al., 2019b; Iung et al., 2020). Due to the favorable genetic correlations between the resilience indicators and the health, longevity, and fertility traits, inclusion of the resilience indicators will assist in genetic improvement of health, longevity, and fertility and vice versa. Furthermore, inclusion of milk yield and DMI, which were unfavorably correlated with the resilience indicators, will slow down progress in resilience (Berghof et al., 2019b; Iung et al., 2020), but will make it possible to select animals that combine good resilience with good feed efficiency and high milk yield. Inclusion of the resilience indicators into the total merit index will therefore help to maximize trouble-free lifetime production.

\section{CONCLUSIONS}

For each of the 2 resilience indicators, LnVar and $\mathrm{r}_{\text {auto }}$, heritabilities were similar in different periods of the lactation. Heritabilities were higher in full lactation 1, but decreased over lactations. For each of the resilience indicators, genetic correlations between different periods of lactation 1 and between different lactations were strong $(0.65-0.99)$, but decreased when periods were further apart in time. These results suggest that resilience is not the same trait throughout life, but is still genetically similar. As a resilience indicator for breeding, LnVar based on full lactation is preferred over LnVar based on periods of the lactation, because of a higher heritability and stronger and favorable genetic correlations with health and longevity. $R_{\text {auto }}$ based on period 1 of the lactation seemed to be more informative about resilience than $r_{\text {auto }}$ based on other periods, but genetic correlations with health and longevity were still weak. Based on these results, the usefulness of $r_{\text {auto }}$ as a resilience indicator for breeding remains to be determined. An index of EBV for LnVar based on lactations 1,2 , and 3 is recommended to optimally improve resilience throughout the first 3 lactations.

\section{ACKNOWLEDGMENTS}

We acknowledge the Dutch Ministry of Economic Affairs (TKI Agri \& Food project 16022) and the Breed4Food partners Cobb Europe (Boxmeer, the Netherlands), CRV (Arnhem, the Netherlands), Hendrix Genetics (Boxmeer, the Netherlands), and Topigs Norsvin (Beuningen, the Netherlands) for their financial support. In addition, we acknowledge European Union's Horizon 2020 research and innovation program GenTORE (grant agreement No. 727213) for their financial support. Furthermore, we acknowledge Cooperation CRV and CRV BV for providing the data. Finally, we acknowledge the Breed4Food partners and Cooperation CRV and CRV BV for their help in interpreting the results. The authors have not stated any conflicts of interest.

\section{REFERENCES}

Aguilar, I., I. Misztal, and S. Tsuruta. 2009. Genetic components of heat stress for dairy cattle with multiple lactations. J. Dairy Sci. 92:5702-5711. https://doi.org/10.3168/jds.2008-1928. 
Aho, A. V., B. W. Kernighan, and P. J. Weinberger. 1988. The AWK Programming Language. Addison-Wesley Publishing Company, Reading, MA.

Alkhoder, H., R. Pijl, and H. H. Swalve. 2010. Estimation of Genetic Parameters for Claw Disorders in Dairy Cows Using a Random Regression Model. Abstract no. 139 in Proceedings of the 9th World Congress on Genetics Applied to Livestock Production, Leipzig, Germany.

Banos, G., and G. E. Shook. 1990. Genotype by environment interaction and genetic correlations among parities for somatic cell count and milk yield. J. Dairy Sci. 73:2563-2573. https://doi.org/10 .3168/jds.S0022-0302(90)78942-4.

Barker, J. S. F., and A. Robertson. 1966. Genetic and phenotypic parameters for the first three lactations in Friesian cows. Anim. Sci. 8:221-240. https://doi.org/10.1017/S0003356100034607.

Berghof, T. V. L., H. Bovenhuis, and H. A. Mulder. 2019a. Body weight deviations as indicator for resilience in layer chickens. Front. Genet. 10:1216. https://doi.org/10.3389/fgene.2019.01216.

Berghof, T. V. L., M. Poppe, and H. A. Mulder. 2019b. Opportunities to improve resilience in animal breeding programs. Front. Genet. 9:692. https://doi.org/10.3389/fgene.2018.00692.

Bloemhof, S., G. de Jong, and Y. de Haas. 2009. Genetic parameters for clinical mastitis in the first three lactations of Dutch Holstein cattle. Vet. Microbiol. 134:165-171. https://doi.org/10.1016/j .vetmic.2008.09.024.

Bohlouli, M., J. Shodja, S. Alijani, and A. Eghbal. 2013. The relationship between temperature-humidity index and test-day milk yield of Iranian Holstein dairy cattle using random regression model. Livest. Sci. 157:414-420. https://doi.org/10.1016/j.livsci.2013.09 .005 .

Brotherstone, S., I. M. S. White, and K. Meyer. 2000. Genetic modelling of daily milk yield using orthogonal polynomials and parametric curves. Anim. Sci. 70:407-415. https://doi.org/10.1017/ S1357729800051754.

Carlén, E., K. Grandinson, U. Emanuelson, and E. Strandberg. 2009. Random regression models for genetic evaluation of clinical mastitis in dairy cattle. Animal 3:1100-1108. https://doi.org/10.1017/ S1751731109004601.

Carlén, E., E. Strandberg, and A. Roth. 2004. Genetic parameters for clinical mastitis, somatic cell score, and production in the first three lactations of Swedish Holstein cows. J. Dairy Sci. 87:30623070. https://doi.org/10.3168/jds.S0022-0302(04)73439-6.

Chang, Y. M., D. Gianola, B. Heringstad, and G. Klemetsdal. 2004 Longitudinal analysis of clinical mastitis at different stages of lactation in Norwegian Cattle. Livest. Prod. Sci. 88:251-261. https:/ /doi.org/10.1016/j.livprodsci.2003.11.007.

Colditz, I. G., and B. C. Hine. 2016. Resilience in farm animals: Biology, management, breeding and implications for animal welfare. Anim. Prod. Sci. 56:1961-1983. https://doi.org/10.1071/AN15297.

CRV. 2015. E-30 Claw health index. Accessed March 3, 2020. https:// cooperatiecrv-be6.kxcdn.com/wp-content/uploads/2018/10/E_30 -Claw-Health-Index-apr2017-_en.pdf.

CRV. 2017. E-27 Breeding value udder health. Accessed March 3, 2020. https://cooperatiecrv-be6.kxcdn.com/wp-content/uploads/ 2018/10/E_27-Udder-Health-April-2017_en.pdf.

CRV. 2018a. E-7 Breeding value estimation of milk production traits with test-day model. Accessed March 3, 2020. https:// cooperatiecrv-be6.kxcdn.com/wp-content/uploads/2018/10/E_07 -tdm-apr-2018_EN.pdf.

CRV. 2018b. E- 8 Breeding value estimation for conformation traits. Accessed March 3, 2020. https://cooperatiecrv-be6.kxcdn.com/wp -content/uploads/2018/10/E_08_eng_augustus-2018.pdf.

CRV. 2018c. E-40 Breeding value dry matter intake. Accessed March 3, 2020. https://cooperatiecrv-be6.kxcdn.com/wp-content/uploads/ 2018/12/E_40-Feed-intake-dec-2018-1.pdf.

CRV. 2019a. E-17 Breeding value fertility. Accessed March 3, 2020. https://cooperatiecrv-be6.kxcdn.com/wp-content/uploads/2019/ 04/E_17-vru_apr2019_en-.pdf.

CRV. 2019b. E-19 Breeding value for longevity (LON). Accessed March 3, 2020. https://cooperatiecrv-be6.kxcdn.com/wp-content/ uploads/2019/08/E_19-Longevity_aug2019_eng.pdf. de Haas, Y., R. F. Veerkamp, H. W. Barkema, Y. T. Gröhn, and Y. H. Schukken. 2004. Associations between pathogen-specific cases of clinical mastitis and somatic cell count patterns. J. Dairy Sci. 87:95-105. https://doi.org/10.3168/jds.S0022-0302(04)73146-X.

Detilleux, J., P. Leroy, and D. Volckaert. 1997. Alternative use of somatic cell counts in genetic selection for mastitis resistance. Pages 34-41 in Proceedings of the International Workshop on Genetic Improvement of Functional Traits in Cattle, Uppsala, Sweden. Interbull, Uppsala, Sweden.

Elgersma, G. G., G. de Jong, R. van der Linde, and H. A. Mulder. 2018. Fluctuations in milk yield are heritable and can be used as a resilience indicator to breed healthy cows. J. Dairy Sci. 101:12401250. https://doi.org/10.3168/jds.2017-13270.

Elsaid, R., A. Sabry, M. S. Lund, and P. Madsen. 2011. Genetic analysis of somatic cell score in Danish dairy cattle using random regression test-day model. Livest. Sci. 140:95-102. https://doi.org/ 10.1016/j.livsci.2011.02.013.

Friggens, N. C., P. Berg, P. Theilgaard, I. R. Korsgaard, K. L. Ingvartsen, P. Løvendahl, and J. Jensen. 2007. Breed and parity effects on energy balance profiles through lactation: Evidence of genetically driven body energy change. J. Dairy Sci. 90:5291-5305. https: //doi.org/10.3168/jds.2007-0173.

Gernand, E., D. A. Döhne, and S. König. 2013. Genetic background of claw disorders in the course of lactation and their relationships with type traits. J. Anim. Breed. Genet. 130:435-444. https://doi .org/10.1111/jbg.12046.

Gernand, E., and S. König. 2014. Random regression test-day model for clinical mastitis: Genetic parameters, model comparison, and correlations with indicator traits. J. Dairy Sci. 97:3953-3963. https://doi.org/10.3168/jds.2013-7830.

Gilmour, A. R., B. J. Gogel, B. R. Cullis, S. J. Welham, and R Thompson. 2015. ASReml User Guide Release 4.1 Functional Specification. VSN International Ltd., Hemel Hempstead, UK.

Haile-Mariam, M., M. E. Goddard, and P. J. Bowman. 2001. Estimates of genetic parameters for daily somatic cell count of Australian dairy cattle. J. Dairy Sci. 84:1255-1264. https://doi.org/10 .3168/jds.S0022-0302(01)74587-0.

Harder, I., E. Stamer, W. Junge, and G. Thaller. 2020. Estimation of genetic parameters and breeding values for feed intake and energy balance using pedigree relationships or single-step genomic evaluation in Holstein Friesian cows. J. Dairy Sci. 103:2498-2513. https: //doi.org/10.3168/jds.2019-16855.

Heringstad, B., Y. M. Chang, D. Gianola, and G. Klemetsdal. 2004. Multivariate threshold model analysis of clinical mastitis in multiparous Norwegian Dairy Cattle. J. Dairy Sci. 87:3038-3046. https://doi.org/10.3168/jds.S0022-0302(04)73436-0.

Ingvartsen, K. L., R. J. Dewhurst, and N. C. Friggens. 2003. On the relationship between lactational performance and health: Is it yield or metabolic imbalance that cause production diseases in dairy cattle? A position paper. Livest. Prod. Sci. 83:277-308. https:// doi.org/10.1016/S0301-6226(03)00110-6.

Iung, L. H. S., R. Carvalheiro, H. H. R. Neves, and H. A. Mulder. 2020. Genetics and genomics of uniformity and resilience in livestock and aquaculture species: A review. J. Anim. Breed. Genet. 137:263-280. https://doi.org/10.1111/jbg.12454.

Jamrozik, J., and L. R. Schaeffer. 1997. Estimates of genetic parameters for a test day model with random regressions for yield traits of first lactation Holsteins. J. Dairy Sci. 80:762-770. https://doi .org/10.3168/jds.S0022-0302(97)75996-4.

Klei, L., and K. A. Weigel. 1998. A method to estimate correlations among traits in different countries using data on all bulls. Interbull Bull. 17:8-14.

Koenen, E. P. C., and R. F. Veerkamp. 1998. Genetic covariance functions for live weight, condition score, and dry-matter intake measured at different lactation stages of Holstein Friesian heifers. Livest. Prod. Sci. 57:67-77. https://doi.org/10.1016/S0301 $-6226(98) 00159-6$.

Koenker, R. 2018. quantreg: Quantile Regression. R package version 5.36. https://CRAN.R-project.org/package=quantreg. 
Larroque, H., and V. Ducrocq. 1999. An indirect approach for the estimation of genetic correlations between longevity and other traits. Interbull Bull. 21:128-136.

Manzanilla Pech, C. I. V., R. F. Veerkamp, M. P. L. Calus, R. Zom, A. van Knegsel, J. E. Pryce, and Y. de Haas. 2014. Genetic parameters across lactation for feed intake, fat- and protein-corrected milk, and liveweight in first-parity Holstein cattle. J. Dairy Sci. 97:5851-5862. https://doi.org/10.3168/jds.2014-8165.

Maust, L. E., R. E. McDowell, and N. W. Hooven. 1972. Effect of summer weather on performance of Holstein cows in three stages of lactation. J. Dairy Sci. 55:1133-1139. https://doi.org/10.3168/ jds.S0022-0302(72)85635-2.

Meyer, K., and W. G. Hill. 1997. Estimation of genetic and phenotypic covariance functions for longitudinal or 'repeated' records by restricted maximum likelihood. Livest. Prod. Sci. 47:185-200. https: //doi.org/10.1016/S0301-6226(96)01414-5.

Mrode, R. A., and G. J. T. Swanson. 2003. Estimation of genetic parameters for somatic cell count in the first three lactations using random regression. Livest. Prod. Sci. 79:239-247. https://doi.org/ 10.1016/S0301-6226(02)00169-0.

Muuttoranta, K., A. M. Tyrisevä, E. A. Mäntysaari, J. Pösö, G. P. Aamand, and M. H. Lidauer. 2019. Genetic parameters for female fertility in Nordic Holstein and Red Cattle dairy breeds. J. Dairy Sci. 102:8184-8196. https://doi.org/10.3168/jds.2018-15858.

Negussie, E., I. Strandén, and E. A. Mäntysaari. 2008. Genetic association of clinical mastitis with test-day somatic cell score and milk yield during first lactation of Finnish Ayrshire cows. J. Dairy Sci. 91:1189-1197. https://doi.org/10.3168/jds.2007-0510.

Poppe, M., R. F. Veerkamp, M. L. van Pelt, and H. A. Mulder. 2020. Exploration of variance, autocorrelation, and skewness of deviations from lactation curves as resilience indicators for breeding. J. Dairy Sci. 103:1667-1684. https://doi.org/10.3168/jds.2019-17290.

Pösö, J., and E. A. Mäntysaari. 1996. Relationships between clinical mastitis, somatic cell score, and production for the first three lactations of Finnish Ayrshire. J. Dairy Sci. 79:1284-1291. https:// doi.org/10.3168/jds.S0022-0302(96)76483-4.

Putz, A. M., J. C. S. Harding, M. K. Dyck, F. Fortin, G. S. Plastow, J. C. M. Dekkers, and PigGen Canada. 2019. Novel resilience phenotypes using feed intake data from a natural disease challenge model in wean-to-finish pigs. Front. Genet. 9:660. https://doi.org/ 10.3389 /fgene. 2018.00660
Santana, M. L., A. B. Bignardi, R. J. Pereira, G. Stefani, and L. El Faro. 2017. Genetics of heat tolerance for milk yield and quality in Holsteins. Animal 11:4-14. https://doi.org/10.1017/ S1751731116001725.

Schaeffer, L. R. 1994. Multiple-country comparison of dairy sires. J. Dairy Sci. 77:2671-2678. https://doi.org/10.3168/jds.S0022 -0302(94)77209-X.

Urioste, J. I., J. Franzén, J. J. Windig, and E. Strandberg. 2012. Genetic relationships among mastitis and alternative somatic cell count traits in the first 3 lactations of Swedish Holsteins. J. Dairy Sci. 95:3428-3434. https://doi.org/10.3168/jds.2011-4739.

Vosman, J., G. De Jong, H. Eding, and H. Knijn. 2015. Genetic evaluation for ketosis in the Netherlands based on FTIR measurements. Interbull Bull. 49:1-5.

Wathes, D. C., Z. Cheng, N. Bourne, V. J. Taylor, M. P. Coffey, and S. Brotherstone. 2007. Differences between primiparous and multiparous dairy cows in the inter-relationships between metabolic traits, milk yield and body condition score in the periparturient period. Domest. Anim. Endocrinol. 33:203-225. https://doi.org/10.1016/j domaniend.2006.05.004.

Weller, J. I., and E. Ezra. 2004. Genetic analysis of the Israeli Holstein dairy cattle population for production and nonproduction traits with a multitrait animal model. J. Dairy Sci. 87:1519-1527. https: //doi.org/10.3168/jds.S0022-0302(04)73303-2.

Whittemore, C. T. 2009. Allocation of resources to growth. Pages 130-146 in Resource Allocation Theory Applied to Farm Animal Production. W. M. Rauw, ed. CABI, Wallingford, UK.

Zwald, N. R., K. A. Weigel, Y. M. Chang, R. D. Welper, and J. S. Clay. 2006. Genetic analysis of clinical mastitis data from onfarm management software using threshold models. J. Dairy Sci. 89:330-336. https://doi.org/10.3168/jds.S0022-0302(06)72098-7.

\section{ORCIDS}

M. Poppe @ https://orcid.org/0000-0001-7801-3942

G. Bonekamp (1) https://orcid.org/0000-0003-3621-7853

M. L. van Pelt $\odot$ https://orcid.org/0000-0003-1315-1329

H. A. Mulder (ㄴ) https://orcid.org/0000-0003-2124-4787 


\section{APPENDIX}

Table A1. Phenotypic correlations among periods 1, 2, and 3 of the first lactation and phenotypic correlations between the 3 lactation periods and the full first lactation for the resilience indicators LnVar (natural logtransformed variance of deviations from a lactation curve) and $r_{\text {auto }}$ (lag-1 autocorrelation of deviations from a lactation curve), and for average daily milk yield (ADMY $)^{1}$

\begin{tabular}{llll}
\hline Item & \multicolumn{1}{c}{ LnVar } & \multicolumn{1}{c}{$\mathrm{r}_{\text {auto }}$} & ADMY \\
\hline Lactation period 1 and 2 & $0.29(0.0017)$ & $0.24(0.0017)$ & $0.83(0.0012)$ \\
Lactation period 1 and 3 & $0.21(0.0023)$ & $0.17(0.0017)$ & $0.67(0.0021)$ \\
Lactation period 2 and 3 & $0.33(0.0019)$ & $0.29(0.0030)$ & $0.86(0.0012)$ \\
Lactation period 1 and full lactation 1 & $0.76(0.00098)$ & $0.73(0.0014)$ & $0.89(0.00066)$ \\
Lactation period 2 and full lactation 1 & $0.69(0.0012)$ & $0.65(0.0021)$ & $0.97(0.00026)$ \\
Lactation period 3 and full lactation 1 & $0.64(0.0019)$ & $0.60(0.0019)$ & $0.92(0.00076)$ \\
\hline
\end{tabular}

${ }^{1}$ Phenotypic correlations are weighted means of trivariate analyses of 5 subsets of the data; empirical SE are between parentheses.

Table A2. Phenotypic correlations between lactations 1, 2, and 3 for the resilience indicators LnVar (natural log-transformed variance of deviations from a lactation curve) and $\mathrm{r}_{\text {auto }}$ (lag-1 autocorrelation of deviations from a lactation curve), and for average daily milk yield (ADMY) ${ }^{1}$

\begin{tabular}{lccc}
\hline Item & LnVar & $\mathrm{r}_{\text {auto }}$ & ADMY \\
\hline Lactation 1 and 2 & $0.33(0.0033)$ & $0.24(0.0033)$ & $0.57(0.0041)$ \\
Lactation 1 and 3 & $0.29(0.0075)$ & $0.16(0.0028)$ & $0.53(0.0036)$ \\
Lactation 2 and 3 & $0.36(0.0052)$ & $0.28(0.0045)$ & $0.57(0.0069)$ \\
\hline
\end{tabular}

${ }^{1}$ Phenotypic correlations are weighted means of trivariate analyses of 5 subsets of the data; empirical SE are between parentheses. LnVar and $r_{\text {auto }}=$ weighted mean of phenotypic correlations of 4 subsets of complete data set instead of 5 .

Table A3. Phenotypic correlations among LnVar (natural log-transformed variance of deviations from a lactation curve), $\mathrm{r}_{\text {auto }}$ (lag-1 autocorrelation of deviations from a lactation curve), and ADMY (average daily milk yield) for periods 1,2 , and 3 of the first lactation, and for full lactation 1,2 , and $3^{1}$

\begin{tabular}{lccc}
\hline Period & LnVar and $\mathrm{r}_{\text {auto }}$ & LnVar and ADMY & $\mathrm{r}_{\text {auto }}$ and ADMY \\
\hline Lactation period 1 & $0.11(0.0025)$ & $0.088(0.0033)$ & $0.072(0.0041)$ \\
Lactation period 2 & $0.14(0.0041)$ & $0.16(0.0033)$ & $-0.0061(0.0025)$ \\
Lactation period 3 & $0.11(0.0017)$ & $0.26(0.0034)$ & $0.038(0.0020)$ \\
Lactation 1 & $0.10(0.0065)$ & $0.22(0.034)$ & $0.067(0.0037)$ \\
Lactation 2 & $0.18(0.0072)$ & $0.29(0.0034)$ & $0.0049(0.0048)$ \\
Lactation 3 & $0.24(0.0069)$ & $0.24(0.0057)$ & $-0.034(0.0027)$ \\
\hline
\end{tabular}

${ }^{1}$ Phenotypic correlations are weighted means of trivariate analyses of 5 subsets of the data; empirical SE are between parentheses. 